\title{
Research on the Construction of Practical Teaching System of Application-Oriented Undergraduate E-Commerce Specialty Based on OBE Concept
}

\author{
Mengmegn Zhang ${ }^{1, a}$
}

${ }^{1}$ College of Logistics and E-commerce, Henan University of Animal Husbandry and Economy, Zhengzhou 450044, China

a19805264@qq.com

*Mengmeng Zhang

Keywords: OBE, Learning output; E-commerce; Practical teaching

\begin{abstract}
Scientifically and rationally setting up an applied undergraduate practice teaching system is the core task of deepening the reform of the talent training model and continuously improving the quality of personnel training. Based on the OBE concept and the investigation of the talent needs of employers, colleges and universities, graduates and students in school, this paper redefines the training objectives of Application-oriented Undergraduate e-commerce talents, and sets 13 graduation requirements from three aspects of knowledge structure, ability structure and quality structure based on the training objectives, and then constructs the practical teaching system of e-commerce specialty. And the corresponding relationship matrix with graduation requirements. In order to ensure the good operation of the practical teaching system, the guarantee measures are formulated from three aspects: Innovation of curriculum evaluation method, rational design of practice content and promotion of school enterprise collaborative education.
\end{abstract}

\section{基于OBE理念的应用型本科电子商务专业实践教学体系构建研究}

\author{
张朦朦 ${ }^{1,}$ a \\ 1河南牧业经济学院 物流与电商学院, 河南 郑州 450044 \\ a19805264@qq.com \\ *张朦蒙
}

关键词: OBE理念; 学习产出; 电子商务; 实践教学

中文摘要. 科学合理地设置应用型本科实践教学体系是地方本科院校深化人才培养模式改 革, 不断提升人才培养质量的核心任务。本文借鉴OBE理念, 在对用人单位、高校、毕业生/ 在校生进行人才需求调研的基础上, 重新设定了应用型本科电子商务专业人才培养目标, 并 基于人才培养目标从知识结构、能力结构和素质结构三个方面设定了13项毕业要求，进而构 建了电子商务专业的实践教学体系及其与毕业要求的对应关系矩阵。为保证该实践教学体系 良好运行, 并从创新课程评价方式、合理设计实践内容、推进校企协同育人三个方面制定了 保证措施。

\section{1. 引言}

电子商务专业作为一个由技术和市场双重驱动的专业，必须对接行业企业，根据产业发 展对人才的实际需求进行人才培养, 以提供高质量的复合社会需求的本科应用型人才。然而, 
目前应用型本科电子商务专业的实践教学体系仍基于传统教育模式进行设置, 存在实践课程 培养目标不明确, 理论环节与实践环节缺乏有效整合, 评价体系不完善等问题, 基于 OBE理 念的应用型本科电子商务专业实践教学体系构建思路将由学习产出反向驱动整个教学过程的 重构，对于培养应用型人才有显著的促进作用。

\section{2. 基于学习产出的教育模式和传统教育模式的区别}

传统的人才培养是将学科知识体系或教师经验作为驱动教育系统运作的动力, 这种基于 课程的教学过程设计更加强调教师希望的学习内容, 并以考试和分数对学生进行评价。基于 学习产出的教育模式 (Outcome-Based Education, OBE) 最早应用于美国和澳大利亚的基础 教育改革, 该模式是以预期学习产出为中心来组织、实施和评价教育的结构模式, 即在对人 才需求充分调研的基础上确定人才培养目标和毕业要求, 并以此构建整个教学计划, 这种由 学习产出“反向驱动”整个教学过程的结构与系统将对培养适应企业需求的高素质应用型人才 产生显著的促进作用 ${ }^{[1-2]}$ 。

\section{1 电子商务专业人才需求调研分析}

通过对用人单位和已毕业学生的调研可以发现, 66.7\%的被调研者认为电子商务专业的毕 业生在工作中表现出理论知识与实际工作脱节; $56.7 \%$ 的被调研者认为毕业生的实践能力较 差; $48.2 \%$ 的被调研者认为毕业生不具备基本的办公技能, 无法熟练操作常用的办公软件; $42.5 \%$ 的被调研者认为毕业生沟通能力需要进一步提高; $38.2 \%$ 的被调研者认为毕业生通常眼 高手低，不愿意从基层做起。

为了将电子商务专业人才培养与实际工作岗位相匹配，特针对用人单位和电子商务行业 从业者进行了专业能力重要程度的调查, 主要调查的专业技能有: 信息技术与工具应用; 数 据挖掘与数据分析; 时间及资源管理; 网站策划与运营; 电商平台策划运营; 网络推广; 商 品信息采集及视觉营销创意与实现; 客户信息搜集、客户服务及客户关系管理; 网络客群、 竞争者分析及网络市场定位; 商业智能分析与应用; 产品策划、产品商业化及运营管理; 电 子商务推销、促销活动策划与执行; 电子商务相关法律运用等。其中认为数据挖掘与数据分 析; 网站策划与运营; 电商平台策划运营; 网络推广; 商业智能分析与应用; 客户信息搜集、 客户服务及客户关系管理; 网络客群、竞争者分析及网络市场定位; 产品策划、产品商业化 及运营管理; 电子商务相关法律运用等技能是必须具备的, 而且有超过 $50 \%$ 的被调研者认为 这些技能是极其重要的。另外，有超过 $30 \%$ 的被调研者认为信息技术与工具应用、时间及资 源管理、商品信息采集及视觉营销创意与实现、电子商务推销、促销活动策划与执行等技能 是极为重要的。

对于电子商务专业人才培养目标、课程体系设置、毕业要求设定，根据高校调研结果分 析, $67.2 \%$ 的被调研高校认为现有的电子商务专业课程体系设置无法完全对人才培养目标进行 支撑，且人才培养目标与毕业要求设定存在脱节; $58.2 \%$ 的被调研高校认为现有的电子商务专 业无法根据社会需求开设应用性强且具备前瞻性的课程，同时在校企合作进行人才培养、师 资培养方面举步维艰。根据学生调研结果的分析, 超过 $50 \%$ 的学生认为电子商务专业现有课 程体系重复内容过多, 部分课程无法培养实际工作岗位所需要的技能和能力, 以及理论知识 过多, 实践课程太少的情况。

\section{2 基于需求调查的应用型本科电子商务专业人才培养目标设定}

培养目标是对电子商务专业学生毕业5年左右所能够达到的职业和专业成就的总体描述。 基于以上对用人单位、高校及学生的调研, 应用型本科电子商务专业人才的培养目标为: 能 够灵活运用电子商务领域的相关知识, 分析和解决电子商务活动中存在的问题, 熟悉、解读 和执行电子商务行业的政策法规; 能够确立电子商务发展的战略目标, 进行电子商务决策规 
划, 制订电子商务运营及推广策略, 能够负责各项管理制度、流程、标准的建立及监控, 做 好电子商务平台的规划、搭建、运营、优化工作，加强渠道建设、市场开拓、品牌管理、客 户关系管理及大客户关系的维护，整合内外部资源，为公司的产品和服务寻找新的业务增长 点, 能够胜任电子商务主管、电子商务经理、电子商务运营总监等中高层职位; 具有较强的 团队合作能力和强烈的社会责任感, 具有过硬的心理素质, 具备较强的协调、沟通及执行能 力, 具有良好的职业操守, 能够遵守相关法律法规; 具有一定的全局意识和创新能力, 具备 较强的可持续发展能力, 善于把握国内外电子商务的现状及发展趋势, 不断加强自主学习和 终身学习, 提升自身能力, 适应职业发展。

\section{3 人才培养目标导向下的应用型本科电子商务专业毕业要求设定}

基于 OBE 理念及电子商务专业在对用人单位、高校、毕业生、在校生调研的基础上，结 合本专业的人才培养目标, 需要构建为达成目标所需完成的毕业要求以及二者之间的对应关 系矩阵。应用型本科电子商务专业所需达到的毕业要求分为知识、能力和素养三个层面, 具 体的毕业要求有 13 点 ${ }^{[3-4]}$ 。

\subsection{1 知识结构的毕业要求设定}

在知识结构方面, 电子商务专业毕业要求有：(1)掌握管理学、计算机科学技术和经济学 等学科的基础理论和专业知识; (2)掌握电子商务规划、电子商务运营、电子商务管理、网络 营销、大数据分析等电子商务类专业理论知识与科学方法; (3)掌握电子商务系统设计与开发、 视觉设计、平台优化的基本技术知识; (4)掌握电子商务领域的政策、标准、法律法规; (5)了 解电子商务新兴产业动态, 注重产业技术和商业模式创新并及时掌握相关的理论与技术知识。 2.3.2 能力结构的毕业要求设定

在能力结构方面, 电子商务专业毕业要求有：(1)具有较强的自主学习能力、沟通与写作 能力、信息技术应用能力; (2)具有较好的团队协作能力、组织协调能力、应变及抗压能力; (3)具有较强的电子商务规划、运营、设计与管理能力; (4)具有综合运用所学知识分析和解决 问题的能力; (5)具有分析把握电子商务发展特点、趋势和创新的能力。

\subsection{3 素质结构的毕业要求设定}

在素质结构方面, 电子商务专业毕业要求有： 1要树立正确的世界观、人生观和价值观, 富有强烈的社会责任感和奉献精神, 具有健全的人格, 具有良好的思想道德素养和健全的法 制意识、具有良好的身体素质和心理素质; (2)要具有高度的敬业精神和团结协作精神、诚实 守信, 具有强烈的责任心、服务意识、求实创新意识; (3)要热爱本专业, 有专业理想, 养成 解决本专业基本问题的素质。

\section{4 基于毕业要求的应用型本科电子商务专业实践教学课程体系设计}

基于电子商务专业学生的毕业要求, 需要合理设置其实践教学体系, 并且需要将实践教 学体系中的每门课程与学生毕业要求中所获知识、能力和素质建立对应关系, 进而实现毕业 要求与实践课程体系的良好对接。基于电子商务专业学生毕业要求的实践教学体系以及与毕 业要求的对应关系矩阵如表 $1 、 2$ 所示 ${ }^{[5-6]}$ 。

表1 应用型本科电子商务专业实践教学体系

\begin{tabular}{|c|c|c|c|c|c|c|c|}
\hline \multirow{2}{*}{$\begin{array}{l}\text { 课程 } \\
\text { 性质 }\end{array}$} & \multirow{2}{*}{ 课程名称 } & \multirow{2}{*}{ 总学分 } & \multirow{2}{*}{ 总学时 } & \multicolumn{2}{|c|}{ 课内学时 } & \multirow{2}{*}{ 考核方式 } & \multirow{2}{*}{ 开课学期 } \\
\hline & & & & 理论 & 实践 & & \\
\hline \multirow{5}{*}{$\begin{array}{l}\text { 专业 } \\
\text { 基础 } \\
\text { 实验 }\end{array}$} & 管理学 & 3 & 48 & 40 & 8 & 考查 & 1 \\
\hline & 程序设计基础 & 3 & 48 & 32 & 16 & 考试 & 3 \\
\hline & 网络技术及应用 & 2 & 32 & 24 & 8 & 考查 & 4 \\
\hline & 物流学 & 2 & 32 & 24 & 8 & 考试 & 5 \\
\hline & 会计学 & 3 & 48 & 32 & 16 & 考查 & 6 \\
\hline \multirow{2}{*}{$\begin{array}{l}\text { 专业 } \\
\text { 教育 }\end{array}$} & 商务网站网页设计 & 3 & 48 & 0 & 48 & 考试 & 4 \\
\hline & 电子商务系统分析与设计 & 2 & 32 & 24 & 8 & 考试 & 5 \\
\hline
\end{tabular}




\begin{tabular}{|c|c|c|c|c|c|c|c|}
\hline \multirow[t]{5}{*}{ 实验 } & 数据库技术 & 3 & 48 & 32 & 16 & 考试 & 5 \\
\hline & 商务数据分析 & 3 & 48 & 24 & 24 & 考试 & 5 \\
\hline & 网络营销 & 3 & 48 & 32 & 16 & 考试 & 6 \\
\hline & 电子商务案例分析 & 2 & 32 & 24 & 8 & 考试 & 6 \\
\hline & WEB程序设计 & 3 & 48 & 32 & 16 & 考试 & 6 \\
\hline \multirow{4}{*}{$\begin{array}{l}\text { 集中 } \\
\text { 教学 } \\
\text { 实践 }\end{array}$} & 电商平台视觉设计综合 & 3 & 2周 & 0 & 2周 & 考查 & 7 \\
\hline & $\begin{array}{c}\text { 搜索引擎营销 } \\
\end{array}$ & 2 & 1周 & 0 & 1周 & 考查 & 7 \\
\hline & 企业电商运营实战 & 3 & 2周 & 0 & 2周 & 考查 & 7 \\
\hline & 电子商务设计与实现 & 3 & 2周 & 0 & 2周 & 考查 & 7 \\
\hline \multirow{2}{*}{$\begin{array}{l}\text { 校外 } \\
\text { 实习 }\end{array}$} & 专业调研 & 1 & 1周 & 0 & 1周 & 考查 & 1 \\
\hline & 电子商务专业毕业实习 & 4 & 4周 & 0 & 4周 & 考查 & 8 \\
\hline \multirow{3}{*}{$\begin{array}{l}\text { 第二 } \\
\text { 课堂 } \\
\text { 实训 }\end{array}$} & 素质拓展 & 4 & 8周 & 0 & 8周 & 考查 & $1-8$ \\
\hline & 创新创业教育 & 2 & \multicolumn{4}{|c|}{ 参加各类学科专业竞赛、创业训练计划 } & $1-8$ \\
\hline & 第二课堂 & 2 & \multicolumn{4}{|c|}{$\begin{array}{c}\text { 暑假“三下乡”、寒假社会实践立项项目 } \\
\text { 等第一课堂之外的实践活动等 }\end{array}$} & $1-7$ \\
\hline
\end{tabular}

表2 应用型本科电子商务专业实践教学体系与毕业要求的对应关系矩阵

\begin{tabular}{|c|c|c|c|c|c|c|c|c|c|c|c|c|c|c|}
\hline \multirow{3}{*}{$\begin{array}{l}\text { 课程 } \\
\text { 性质 }\end{array}$} & \multirow{3}{*}{ 课程名称 } & \multicolumn{13}{|c|}{ 毕业要求 } \\
\hline & & \multicolumn{5}{|c|}{ 知识结构 } & \multicolumn{5}{|c|}{ 能力结构 } & \multicolumn{3}{|c|}{ 素质结构 } \\
\hline & & (1) & (2) & (3) & (4) & (5) & (1) & (2) & (3) & (4) & (5) & (1) & (2) & (3) \\
\hline \multirow{5}{*}{$\begin{array}{l}\text { 专业 } \\
\text { 基础 } \\
\text { 实验 }\end{array}$} & 管理学 & $\sqrt{ }$ & $\sqrt{ }$ & & $\sqrt{ }$ & $\sqrt{ }$ & $\sqrt{ }$ & & & $\sqrt{ }$ & & $\sqrt{ }$ & $\sqrt{ }$ & \\
\hline & 程序设计基础 & $\sqrt{ }$ & & V & & $\sqrt{ }$ & & & $\sqrt{ }$ & $\sqrt{ }$ & & & $\sqrt{ }$ & $\sqrt{ }$ \\
\hline & 网络技术及应用 & $\sqrt{ }$ & & $\sqrt{ }$ & & $\sqrt{ }$ & & & $\checkmark$ & $\sqrt{ }$ & & & V & $\sqrt{ }$ \\
\hline & 物流学 & $\sqrt{ }$ & & & $\sqrt{ }$ & $\sqrt{ }$ & $\sqrt{ }$ & $\sqrt{ }$ & & $\sqrt{ }$ & $\sqrt{ }$ & $\sqrt{ }$ & & $\sqrt{ }$ \\
\hline & 会计学 & $\sqrt{ }$ & & & $\sqrt{ }$ & $\sqrt{ }$ & $\sqrt{ }$ & $\sqrt{ }$ & & $\sqrt{ }$ & $\sqrt{ }$ & $\sqrt{ }$ & & $\sqrt{ }$ \\
\hline \multirow{7}{*}{$\begin{array}{l}\text { 专业 } \\
\text { 教育 } \\
\text { 实验 }\end{array}$} & 商务网站网页设计 & $\sqrt{ }$ & & $\sqrt{ }$ & & $\sqrt{ }$ & & & $\sqrt{ }$ & $\sqrt{ }$ & & & V & $\sqrt{ }$ \\
\hline & 电子商务系统分析与设计 & $\sqrt{ }$ & $\sqrt{ }$ & $\sqrt{ }$ & & $\sqrt{ }$ & & & $\sqrt{ }$ & $\sqrt{ }$ & & & $\sqrt{ }$ & $\sqrt{ }$ \\
\hline & 数据库技术 & $\sqrt{ }$ & $\sqrt{ }$ & $\sqrt{ }$ & & $\sqrt{ }$ & & & $\sqrt{ }$ & $\sqrt{ }$ & & & $\sqrt{ }$ & $\sqrt{ }$ \\
\hline & 商务数据分析 & $\sqrt{ }$ & $\sqrt{ }$ & & $\sqrt{ }$ & $\sqrt{ }$ & $\sqrt{ }$ & $\sqrt{ }$ & $\sqrt{ }$ & $\sqrt{ }$ & $\sqrt{ }$ & & $\sqrt{ }$ & $\sqrt{ }$ \\
\hline & 网络营销 & $\sqrt{ }$ & $\sqrt{ }$ & & $\sqrt{ }$ & $\sqrt{ }$ & $\sqrt{ }$ & $\sqrt{ }$ & $\sqrt{ }$ & $\sqrt{ }$ & $\sqrt{ }$ & & $\sqrt{ }$ & $\sqrt{ }$ \\
\hline & 电子商务案例分析 & $\sqrt{ }$ & & & $\sqrt{ }$ & $\sqrt{ }$ & $\sqrt{ }$ & & & $\sqrt{ }$ & $\sqrt{ }$ & & $\sqrt{ }$ & $\sqrt{ }$ \\
\hline & WEB程序设计 & $\sqrt{ }$ & $\sqrt{ }$ & V & & $\sqrt{ }$ & & & $\sqrt{ }$ & $\sqrt{ }$ & & & $\sqrt{ }$ & $\sqrt{ }$ \\
\hline \multirow{4}{*}{$\begin{array}{l}\text { 集中 } \\
\text { 教学 } \\
\text { 实践 }\end{array}$} & 电商平台视觉设计综合 & $\sqrt{ }$ & $\sqrt{ }$ & $\sqrt{ }$ & & & & & $\sqrt{ }$ & $\sqrt{ }$ & $\sqrt{ }$ & $\sqrt{ }$ & & $\sqrt{ }$ \\
\hline & 搜索引擎营销 & $\sqrt{ }$ & $\sqrt{ }$ & & $\sqrt{ }$ & $\sqrt{ }$ & $\sqrt{ }$ & $\sqrt{ }$ & $\sqrt{ }$ & $\sqrt{ }$ & $\sqrt{ }$ & & $\sqrt{ }$ & $\sqrt{ }$ \\
\hline & 企业电商运营实战 & $\sqrt{ }$ & $\sqrt{ }$ & $\sqrt{ }$ & $\sqrt{ }$ & $\sqrt{ }$ & $\sqrt{ }$ & $\sqrt{ }$ & $\sqrt{ }$ & & $\sqrt{ }$ & $\sqrt{ }$ & $\sqrt{ }$ & $\sqrt{ }$ \\
\hline & 电子商务设计与实现 & $\sqrt{ }$ & $\sqrt{ }$ & $\sqrt{ }$ & $\sqrt{ }$ & $\sqrt{ }$ & $\sqrt{ }$ & $\sqrt{ }$ & $\sqrt{ }$ & & $\sqrt{ }$ & $\sqrt{ }$ & $\sqrt{ }$ & $\sqrt{ }$ \\
\hline \multirow{2}{*}{$\begin{array}{l}\text { 校外 } \\
\text { 实习 } \\
\end{array}$} & 专业调研 & $\sqrt{ }$ & $\sqrt{ }$ & $\sqrt{ }$ & & $\sqrt{ }$ & $\sqrt{ }$ & $\sqrt{ }$ & $\sqrt{ }$ & & $\sqrt{ }$ & $\sqrt{ }$ & $\sqrt{ }$ & $\sqrt{ }$ \\
\hline & 电子商务专业毕业实习 & $\sqrt{ }$ & $\sqrt{ }$ & $\sqrt{ }$ & $\sqrt{ }$ & $\sqrt{ }$ & $\sqrt{ }$ & $\sqrt{ }$ & $\sqrt{ }$ & & $\sqrt{ }$ & $\sqrt{ }$ & $\sqrt{ }$ & $\sqrt{ }$ \\
\hline \multirow{3}{*}{$\begin{array}{l}\text { 第二 } \\
\text { 课堂 } \\
\text { 实训 }\end{array}$} & 素质拓展 & & & & & & & $\sqrt{ }$ & & $\sqrt{ }$ & & $\sqrt{ }$ & $\sqrt{ }$ & $\sqrt{ }$ \\
\hline & 创新创业教育 & & $\sqrt{ }$ & & & & & $\sqrt{ }$ & & $\sqrt{ }$ & & $\sqrt{ }$ & $\sqrt{ }$ & $\sqrt{ }$ \\
\hline & 第二课堂 & & & & & & & $\sqrt{ }$ & & $\sqrt{ }$ & & $\sqrt{ }$ & $\sqrt{ }$ & $\sqrt{ }$ \\
\hline
\end{tabular}

\section{3. 基于OBE理念的应用型本科电子商务专业实践教学体系配套措施}

\section{1 推进校企协同育人，加快虚拟仿真教学项目开发}

电子商务专业的实践教学要基于企业实际工作过程进行设计开发，除了安排企业电商运 营实战、电子商务设计与实现这类 2-4 周的集中实践教学环节外，还应该基于电子商务发展 趋势，与企业深度合作开发诸如商业智能、电商物流协同、跨境电商运营等虚拟仿真教学项 目, 进而弥补部分实习实训项目条件不具备或实际运行困难而无法有效开展实践教学的情况, 从而持续提高实践教学质量。

\section{2 创新课程评价方式，构建全过程多元化考核体系}

实践教学是电子商务专业教学过程的重要环节, 要综合考查学生运用理论知识解决实际 问题、团队协作、报告撰写、创新创意以及动手操作能力。因此要构建由平时成绩、小组互 
评成绩、项目完成成绩、教师综合评价、创新创意成绩组成的全过程多元化的考核体系, 充 分发挥课程考核机制对学生学习的激励、引导和评价作用。

\section{3 合理设计实验内容, 实现理实教学环节有序结合}

电子商务专业实践教学内容设计要不仅要解决教学内容重复，更要重点解决课内实践与 集中实践、校外实习等环节相关性弱等长期制约该专业实践教学开展的问题。要深入推进校 企协同育人, 重构实践教学体系, 在实际运行中持续改进实践教学体系, 实现理论教学与实 践教学的横向关联与纵向深入。

\section{4. 结语}

基于 OBE 理念的教育模式要求教育者要清晰的构想学生毕业时应达到的能力和水平, 进 而设计适宜的教育体系来保证学生达到这些预期目标。本文基于对用人单位、高校、毕业生/ 在校生的人才需求调研, 重新设定了应用型本科电子商务专业人才培养目标, 并基于人才培 养目标从知识结构、能力结构和素质结构三个方面设定了 13 项毕业要求, 进而构建了电子商 务专业的实践教学体系及其与毕业要求的对应关系矩阵。为保证该实践教学体系良好运行, 并从创新课程评价方式、合理设计实践内容、推进校企协同育人三个方面制定保证措施。

\section{致谢}

河南省教育科学十三五规划课题 (项目编号: 2018-JKGHYB-0309, 2018-JKGHYB-0310); 河南牧业经济学院校级教育教学改革研究项目《基于协同创新理念的应用型本科电子商务专 业立体化实践教学体系构建及实践研究》（项目编号：2018-YBXM-001）、《“一带一路”战 略背景下生鲜电商与冷链物流课程构建研究》（项目编号：2018-YBXM-036）; 河南牧业经 济学院科研创新基金项目（项目编号：XKYCXJJ2017003）; 河南牧业经济学院科研创新团 队建设项目（项目编号：2018KYTD02）。

\section{References}

[1] SPADY W G. Outcome-based education:Critical issues and answers [M]. Arlington: American Association of School Administrators, 1994:1-10.

[2] KISSANE S W B. Systemic approaches to articulating and monitoring student outcomes: Are they consistent with outcome-based education[J]. Studies in Educational Evaluation, 1997,23(1):5-30.

[3] Liu Jing, Liu Yancong. Construction of practical teaching system of industrial design under the concept of obe-cdio [J]. Journal of graphics, 2019,40 (02): 416-421.

[4] Zhang Xia, Hu Jianyuan. Practical teaching system design of human resource management based on OBE concept [J]. Laboratory research and exploration, 2018,37 (06): 227-231 + 263.

[5] Zhang Lei, Wang Hui, Feng Wenlong, Meng Xianfei. Construction of ec-cdio e-commerce talent training mode [J]. Higher engineering education research, 2019 (01): 196-200.

[6] Shang Wei, pan Honghua, Guo Feipeng. Construction of tf-cdio e-commerce curriculum system [J]. Higher engineering education research, 2012 (02): 146-151. 